Deze rubriek is een forum voor debat over kwalitatief methodologische kwesties. Wie een idee heeft voor een thema of wil reageren op een eerder verschenen bijdrage, vragen wij contact op te nemen met Fred Wester: F.Wester@maw.ru.nl.

\title{
'Thick analysis': strategie om de kwaliteit van kwalita- tieve data-analyse te verhogen
}

\author{
AnneLoes van Staa en Jeanine Evers
}

\section{Stelling}

Kwalitatief onderzoek produceert grote hoeveelheden ruwe data, wat kwalitatieve dataanalyse vaak complex en veeleisend maakt en van de onderzoeker(s) flexibiliteit, ervaring en vaardigheden verlangt. Onze stelling is dat in veel kwalitatief onderzoek aan deze complexiteit onvoldoende recht wordt gedaan, doordat in de dagelijkse praktijk vaak door tijdsdruk de pragmatiek overheerst of vaardigheden ontbreken om tot diepgaande analyse te komen. Daarmee gaat veel van de rijkdom en context van kwalitatieve data verloren. Wij pleiten daarom voor het toepassen van het bekende concept 'triangulatie' - traditioneel gedefinieerd als het toepassen van meerdere dataverzamelingsmethoden in een studie - op kwalitatieve data-analyse, om zo de diepte, kwaliteit en eventueel reikwijdte van de bevindingen te vergroten. Analysetriangulatie wordt nog niet veel toegepast, maar is volgens ons een realistische en bruikbare strategie om de methodologische kwaliteit van kwalitatief onderzoek verder te verhogen. Deze strategie is ook geschikt voor onderzoekers die kwalitatief onderzoek doen buiten de 'academie'. Wij werken een en ander hierna uit.

\section{Inleiding}

Data in kwalitatief onderzoek komen vaak uit verschillende bronnen, zoals veldnotities over observaties, interviewtranscripten, andere geschreven bronnen zoals dagboeken, brieven en documenten. Ook foto's, video's en materiële objecten kunnen als onderzoeksdata worden gehanteerd. De grote hoeveelheden te analyseren ruw materiaal die het gevolg zijn, moeten vervolgens op systematische wijze ontleed, herschikt, georganiseerd en geïnterpreteerd worden om de onderzoeksvragen te kunnen beantwoorden. Doel van kwalitatieve data-analyse is te komen tot reductie, interpretatie en reconstructie van verzamelde gegevens in een continu voortschrijdend proces. Maar hoe je dat precies aanpakt, blijft vaak onduidelijk. Voor niet-ingewijden in kwalitatief onderzoek is het lastig om helderheid te krijgen over de precieze 'techniek' van analyseren, omdat er geen consensus is tussen de verschillende stromingen, en omdat kwalitatieve theoretici nogal eens de neiging hebben steeds nieuwe begrippen te ontwikkelen voor bestaande procedures (zie bijvoorbeeld Saldaña, 2009). Voor beginnende onderzoekers maakt dit de zoektocht naar een praktische handleiding voor kwalitatieve data-analyse niet eenvoudiger. 
Bovendien wijden veel geschriften over kwalitatief onderzoek vaak uitgebreide besprekingen aan datacollectie en de onderzoeksopzet, maar zijn ze opmerkelijk kort over de data-analyse, een tendens die al in 1987 door Anselm Strauss werd opgemerkt. Ook in KWALON wordt er maar weinig aandacht aan thema's rond data-analyse besteed. Volgens ons is dit onterecht, omdat data-analyse van grote invloed is op kwaliteit van de bevindingen in kwalitatief onderzoek.

Over de opzet en uitvoering van kwalitatieve data-analyse zijn de laatste jaren in Nederland enkele bruikbare boeken verschenen (Boeije, 2005; Wester \& Peters, 2004). Jammer genoeg geldt voor beide dat ze zich beperken tot de traditie van de gefundeerde theoriebenadering (GT) (Glaser \& Strauss, 1967). Binnen GT wordt er een bepaalde manier van analyseren gehanteerd die start met open coderen, gevolgd door axiaal en selectief coderen. De open codeervorm binnen GT is overigens anders dan de wijze waarop veel onderzoekers in de praktijk 'open' coderen, en ook binnen GT is er discussie over de 'juiste’ werkwijze (Strauss \& Corbin, 1998). In het onderzoeksleven van alledag wordt de strikte vorm van GT vooral toegepast binnen proefschriftonderzoek; ander onderzoek beperkt zich meestal tot een sterk afgezwakte vorm van 'open' coderen of tot een (oppervlakkige) thematische analyse. Toch wordt deze werkwijze regelmatig benoemd als 'GT-onderzoek', waarmee de bekendheid van GT wordt gebruikt om onduidelijke werkwijzen te legitimeren. De rigoureuze inductie van GT wordt echter veelal niet gehaald, en daar zijn goede redenen voor. GT is een tijdrovende, gedetailleerde en ingewikkelde vorm van analyse, die uiteindelijk uitmondt in een aantal centrale categorieën waarmee de data ingedeeld worden. Daarom pleiten wij voor een andere manier om de kwaliteit en diepgang van de analyse te bevorderen, namelijk analysetriangulatie, die wij met een knipoog naar Clifford Geertz (1973), die 'thick description' propageerde voor de etnografie, 'thick analysis' noemen (Evers \& Van Staa, 2010).

\section{Triangulatie}

Triangulatie is binnen kwalitatief onderzoek een algemeen geaccepteerde wijze om de kwaliteit van een onderzoek te verhogen. Denzin (1989) onderscheidt meerdere types triangulatie, hetgeen hij multiple triangulation noemt: bronnentriangulatie, onderzoekerstriangulatie, theoretische triangulatie en methodentriangulatie. Kimchi, Polivka en Stevenson (1991) voegen een vijfde type toe: analysetriangulatie, terwijl Miles en Huberman (1994) nader onderscheid maken tussen triangulatie van databronnen en van datatypen:

- databronnentriangulatie: data worden verzameld met behulp van verschillende steekproefstrategieën, op verschillende momenten in de tijd, in verschillende sociale situaties en bij verschillende personen;

- onderzoekerstriangulatie: in het onderzoeksproject werken meerdere onderzoekers samen aan dataverzameling en analyse;

- theoretische triangulatie: het gebruiken van verschillende theoretische gezichtspunten voor de verzameling en interpretatie van de data;

- methodentriangulatie: het gebruik van meer dan een methode om data te verzamelen, bijvoorbeeld interviews, participerende observaties en videoregistraties; 
- datatypetriangulatie: hierbij gaat het om de verschillende soorten data die worden gebruikt binnen een studie, bijvoorbeeld interview transcripten, visuele data, officiële statistieken. Dit type is het gevolg van methodentriangulatie;

- analysetriangulatie: het gebruik van verschillende analysetechnieken om binnen een dataset op zoek te gaan naar betekenis.

Maso en Smaling (1998) zien methodentriangulatie en onderzoekstriangulatie als manieren om de interne betrouwbaarheid te bevorderen; terwijl bronnentriangulatie en methodentriangulatie (en wij voegen daar analysetriangulatie aan toe) vooral de interne validiteit vergroten. Daarbij kan het gaan om confirmatie van de bevindingen, maar bijvoorbeeld ook om divergentie, het opleveren van uiteenlopende gezichtspunten. Analysetriangulatie vergroot de validiteit dus vooral door te zorgen voor meer complete inzichten en een dieper of breder begrip. Je kijkt steeds met een ander brilletje naar dezelfde data of delen daarvan.

\section{Boekhouder, alchemist of kunstenaar?}

Data-analyse is een actief proces dat werken met de data veronderstelt in de vorm van bewerken en herbewerken, ofwel reduceren en vervolgens weer compliceren van data door te zoeken naar patronen op een hoger abstractieniveau (Coffey \& Atkinson, 1996; Bogdan \& Knopp Biklen, 2007).

Door het analyseproces te zien als werk wordt duidelijk dat kwalitatieve data-analyse geen black box is, maar een geplande en gestructureerde activiteit, waarin verschillende taken worden onderscheiden en ook gereedschap wordt gebruikt - zoals een computerprogramma dat assisteert bij de reorganisatie van de data en het stellen van vragen aan de dataset. Data-analyse vereist zowel vaardigheden als creativiteit: volgens Boeije (2005) is analyseren denken en doen tegelijkertijd. Coffey en Atkinson (1996) onderscheiden twee basisvisies op kwalitatieve analyse: de procedurele visie die de nadruk legt op procedures en processen als coderen, indexeren en categoriseren, versus de creatieve visie waarbij de nadruk ligt op interpretatie van de data en de exploratie van relaties (variabiliteit of overeenkomsten).

Deze visies zijn gerelateerd aan verschillende aspecten van het analytische proces. Marshall (2000) vergelijkt sommige onderzoekers met boekhouders; zij zijn vooral gepreoccupeerd met procedurele aspecten van de analyse (precisie en betrouwbaarheid). Daartegenover staan de alchemisten; zij appreciëren vooral de black-boxcreativiteit en zijn bang dat kwijt te raken bij het gebruik van analysesoftware. De derde categorie die Marshall onderscheidt zijn de kunstenaars, die beide visies combineren; idealiter worden in de data-analyse zowel de transparantie en strengheid van de boekhouder gehanteerd, als het 'out-of-the-box'- denkproces van de alchemist (Evers \& Van Staa, 2010).

\section{Karakteristieken van kwalitatieve data-analyse}

De meeste onderzoekers zullen het erover eens zijn dat uitgebreide data-analyse een tijdverslindend, continu proces is dat niet alleen vaardigheden, maar ook creatief denken vereist. Maar er bestaat verschil van mening over de centrale activiteit van het analyseren 
zelf en de rol van theorie. Hoe pak je het analytische proces aan? Waar en wanneer begin je - en vooral: wanneer eindigt de analyse? Meestal wordt kwalitatieve analyse gezien als een iteratief of cyclisch proces dat gaat van algemenere naar meer specifieke observaties (Creswell, 2007; Flick, 2006). Daarbij stuurt de analyse van reeds verzamelde data de voortgaande dataverzameling. Continue analyse heeft als voordeel dat de onderzoeker terug kan gaan naar het veld, zijn onderzoeksvragen kan verfijnen, hypotheses kan ontwikkelen en nieuwe onderzoekswegen kan inslaan. Maar voor veel onderzoekers die uit een kwantitatieve traditie afkomstig zijn, is deze flexibiliteit ongebruikelijk en wordt het aanpassen van onderzoeksvragen 'en route' als een serieuze bedreiging van de repliceerbaarheid van de resultaten gezien. In de praktijk van alledag is een open-eindebenadering van kwalitatieve analyse en een continu cyclisch proces van dataverzameling en analyse vaak niet haalbaar, en zullen er grenzen zijn aan de dataverzameling. Het beter benutten van de dataset door analysetriangulatie is dan een serieuze optie voor het zo efficiënt mogelijk gebruiken van de bestede onderzoekstijd en -inspanningen. Bovendien verhoogt analysetriangulatie de creativiteit van de onderzoeker en diens inzicht in de onderzochte fenomenen; zowel de alchemist als de boekhouder worden daarmee versterkt, indien de eis van transparantie wordt gevolgd. Kortom, de meerwaarde ervan lijkt evident.

\section{Rol van theorie bij kwalitatieve analyse}

Een ander onderwerp van debat, dat het vraagstuk rond analysetriangulatie overstijgt, betreft het startpunt voor de constructie van analytische categorieën: moeten we beginnen bij de theorie en onze eigen a priori ideeën (deductief), of moeten deze categorieën en analytische begrippen vooral voortkomen en 'oprijzen' uit de data (inductief)? Binnen kwalitatief onderzoek is traditioneel vooral de laatste stroming sterk vertegenwoordigd zoals blijkt uit het feit dat er verschillende interpretatieve, hermeneutische stromingen zijn (zie Flick, 2006; Denzin \& Lincoln, 2005; Bogdan \& Knopp Biklen, 2007). Als voorbeeld bespreken we de GT van Strauss en Corbin (1998), omdat dit verreweg de meest gehanteerde aanpak is.

\section{Inductieve analyse}

In zijn zuiverste vorm is inductieve analyse binnen GT het vanaf de grond opbouwen van een theorie aan de hand van empirische gegevens, 'grounded in the data'. Hierbij is er sprake van een open onderzoeksvraag en worden de begrippen in deze onderzoeksvraag niet vooraf gedefinieerd of geoperationaliseerd. Op basis van 'constante vergelijking', waarbij de onderzoeker voortdurend switcht tussen dataverzameling en data-analyse, wordt er een theorie ontwikkeld (zie ook Boeije, 2005). Een essentiële activiteit van GTonderzoekers is het coderen van de data, dat wil zeggen het 'labelen' van tekstfragmenten. Binnen GT wordt coderen op een specifieke wijze toegepast: de analyse start met een inductief stadium van open coderen en wordt gevolgd door axiaal en selectief coderen, waarmee een toenemende interpretatie en ontwikkeling van 'sensitizing concepts' wordt aangeduid. Binnen GT worden vier fasen onderscheiden (Strauss \& Corbin, 1998; Wester \& Peters, 2004; Boeije, 2005): 
- exploratie (open coderen);

- specificatie (axiaal coderen);

- reductie (selectief coderen);

- integratie.

Door open te coderen start de onderzoeker dicht bij de empirie ('coding up'). Pas gaandeweg worden begrippen op (latent) conceptueel niveau geformuleerd.

$\mathrm{Bij}$ inductieve analyse is de theorie dus het resultaat van data-analyse, er worden 'bottomup' theoretische concepten gegenereerd aan de hand van empirie. Als belangrijkste nadeel van inductieve analyse wordt geclaimd dat - als het al mogelijk is om uit pure data een consistente, valide en bruikbare theorie te ontwikkelen - deze methode zeer tijdrovend is. Idealiter wordt de onderzoeker geacht om door te gaan met de dataverzameling tot er zogeheten 'saturatie' (verzadiging van begrippen) optreedt, in de praktijk is dit moment echter moeilijk te bepalen. Deze open onderzoeks- en analysebenadering past goed bij onderwerpen waarover nog weinig theorie bestaat, maar is tamelijk omslachtig (en contraproductief) als de onderzoeker al beschikt over thema's en concepten die ook gehanteerd zijn bij de dataverzameling.

\section{Deductieve analyse}

In de deductieve aanpak is de theorie het startpunt van de analyse. Doel van de analyse is om ideeën (theorieën) te toetsen, bijvoorbeeld door van een theoretisch kader één of meerdere hypothesen af te leiden en deze aan de hand van de empirische data te verwerpen dan wel aan te nemen (Bryman, 2004; Maso \& Smaling, 1998). Omdat kwalitatief onderzoek ontstaan is als een kritiek op het hypothetisch-deductieve model, is het logisch dat strikt deductieve analyse weinig populair is in kwalitatieve kringen. In de praktijk wordt deductie wel degelijk toegepast, maar dan niet op de rigide wijze zoals dat in kwantitatief onderzoek gebruikelijk is.

LeComte en Schensul (1999) definiëren 'analysis from the top down' als het organiseren van data in categorieën gerelateerd aan het theoretisch kader en de onderzoeksvragen die zijn opgesteld. Zij verzetten zich tegen de 'mystieke' terminologie van onderzoekers die spreken over 'het oprijzen van thema's en patronen uit de data' alsof het wandelaars op het strand zijn die plots tevoorschijn komen uit de mist. In veel gevallen zal de onderzoeker niet 'blanco' aan de analyse starten, maar al ideeën hebben van thema's en concepten. Deductief analyseren maakt gebruik van 'coding down', waarbij onderzoekers bij het coderen een vooraf opgesteld codeboek gebruiken, dat correspondeert met begrippen uit de literatuurstudie of met de conversatiehulp (zie Evers, 2007). Crabtree en Miller (1999) noemen dit de 'template approach'.

Een ander voorbeeld van een meer deductieve analyseaanpak is de 'framework approach' zoals toegepast door Ritchie en Spencer (1993) die bijzonder geschikt is voor praktijkgericht onderzoek. Hierbij wordt een thematisch raamwerk opgesteld op basis van a priori kennis en de doelstellingen van de studie en gecombineerd met thema's die door de respondenten naar voren zijn gebracht. Deze gedetailleerde 'index' van codes wordt in de volgende fase systematisch toegepast op alle data. De volgende stappen zijn 'charting' 
en 'mapping and interpretation' waarin de data steeds verder worden geordend, geabstraheerd en samengevat.

Deze werkwijze lijkt overeen te komen met het standaardwerk van Miles en Huberman over kwalitatieve analyse (1994). In hun aanpak staat het gebruik van schema's, matrices, tabellen en andere vormen van grafische representaties centraal. Deze tabellen en matrices worden niet gevuld met cijfers, maar met tekstfragmenten en citaten. De analyse bestaat uit het steeds verder vullen van de tabellen en het samenvatten van de inhoud in kernbegrippen. Een kruistabel kan bijvoorbeeld bestaan uit verschillende typen respondenten met relevante variabelen, houdingen of gebeurtenissen. Ook network drawings, flowcharts, decision charts worden door Miles en Huberman gepropageerd voor datareductie en presentatie. Voor het opstellen van visuele representaties kan gebruik worden gemaakt van bestaande categorieën en theorieën.

Tegenover de voordelen van het werken met een analysekader staat als nadeel van deductieve analyse dat theorieën, zeker wanneer die in het 'laboratorium' zijn ontwikkeld, vaak weinig of geen empirische validiteit hebben. Zeker in de sociale wetenschappen is dit een veelgehoord kritiekpunt: theoretisch etnocentrisme of conservatisme dreigt (Bryman, 2004; Maso \& Smaling, 1998; Boeije, 2005).

\section{Inductief of deductief?}

Terecht merken diverse auteurs (LeComte \& Schensul, 1999; Bryman, 2004) op dat het zuivere onderscheid tussen deductie en inductie eigenlijk kunstmatig is en leidt tot oversimplificatie. Bij elk inductief onderzoek vindt er op een zeker moment ook deductie plaats (de beginnende theorie ontwikkeld aan de hand van de eerste data wordt getoetst aan de daaropvolgende data) en ook deductieve kwalitatieve analysestrategieën, zoals ze hiervoor besproken zijn, geven ruimte voor inductie (aan de hand van de gegevens worden nieuwe thema's toegevoegd). Maso en Smaling (1998) stellen dat in de wetenschap kennis vrijwel steeds op abductieve wijze wordt gevormd. Ze staan daarom een aanpak voor die zij baseren op de analytische inductie van Znaniecki. Bij de door hen voorgestelde 'kaderanalyse' wordt het vooraf geformuleerde theoretisch kader geconfronteerd met de verzamelde gegevens in de generatiefase, waarna nieuwe kennis wordt gegenereerd in de confrontatiefase. Deze aanpak wordt momenteel verder uitgewerkt door Evers.

In navolging van Maso en Smaling (1998) zien wij kwalitatieve data-analyse niet als een puur inductieve of deductieve onderneming. De opdracht om grote hoeveelheden, meest ongestructureerde data te organiseren op een systematische wijze vraagt zowel om structuur (opgebouwd uit theoretische noties en raamwerken die op deductieve wijze zijn geconstrueerd) als om flexibiliteit (het verkennen van de data met een open geest, dat wil zeggen inductief zonder voorop gezette categorieën). Maar we gaan een stapje verder door te bepleiten dat onderzoekers daarbij bewust meerdere analysestrategieën toepassen. Voorbeelden van wat de combinatie van een inductieve en deductieve werkwijze bij coderen kan opleveren, worden gegeven bij Fereday en Muir-Cochrane (2006) en bij Van Lanen in dit nummer van KWALON, maar zij hanteren daarbij niet verschillende analysestrategieën zoals wij hier bepleiten. 
Er zijn nog veel meer analysestrategieën mogelijk, waarmee de data inhoudelijk of op vormaspecten verschillend worden geanalyseerd. Een overzicht hiervan wordt gegeven in Gbrich (2007); Saldaña geeft allerlei variaties op het thema coderen (2009). Afhankelijk van de onderzoeksvraag zou de onderzoeker op zoek moeten gaan naar passende analysestrategieën (bijvoorbeeld domeinanalyse, metaforenanalyse, discoursanalyse, 'frame' analyse, narratieve analyse om er maar een paar te noemen) om dieper begrip te krijgen van de complexiteit van de sociale fenomenen die worden bestudeerd. Er bestaat geen voorkeur voor de ene analysestrategie boven de andere, al moeten onderzoekers technieken niet willekeurig selecteren. De keuze van een analysestrategie wordt grotendeels bepaald door de aard en de inhoud van de data, de kwaliteit van bestaande theorieën, de analytische vaardigheid van de onderzoeker, en niet op de laatste plaats, door de beschikbare tijd.

In de cursus kwalitatieve analyse van KWALON passen cursisten verschillende analysestrategieën toe op een kleine dataset, namelijk open en thematisch coderen in de pragmatische variant, axiaal coderen, metaforenanalyse en argumentatieanalyse. Al bij de analyse van een paar krantenartikelen geeft het toepassen van verschillende strategieën een grote diversiteit aan inzichten over de data, waarmee het begrip van de onderzochte kwestie wordt vergroot en nieuwe gezichtspunten ontstaan of nuances worden aangebracht.

\section{Conclusie}

Kwalitatieve analyse is een continu proces dat tijdrovend en arbeidsintensief is en een open, reflexieve houding van de onderzoeker vereist. In de praktijk stelt dit veel onderzoekers voor dilemma's en lopen ze vast in het 'hoe' van de analyse. Wij stellen daarom de volgende voorwaarden aan goede kwalitatieve data-analyse:

- een combinatie van vaardigheden en creativiteit bij de onderzoeker;

- een uitgebreide en systematische aanpak, die niet rigide is;

- een combinatie van inductieve (datagestuurde) en deductieve (theoriegedreven) methoden;

- het toepassen van analysetriangulatie.

Dit zouden wij 'thick analysis' willen noemen, en dat kan helpen goed kwalitatief onderzoek te produceren.

De auteurs bedanken Martijn van Lanen voor zijn ideeën en suggesties bij de totstandkoming van dit artikel.

\section{Literatuur}

Boeije, H.R. (2005). Analyseren in kwalitatief onderzoek: denken en doen. Amsterdam: Boom Onderwijs.

Bogdan, R.C. \& Knopp Biklen, S. (2007). Qualitative research for education. An introduction to theories and methods. Boston: Pearson/Allyn \& Bacon.

Bryman, A. (2004). Social research methods. Oxford: Oxford University Press. 
Crabtree, B. \& Miller, W. (1999). A template approach to text analysis: Developing and using codebooks. In B. Crabtree \& W. Miller (Eds.), Doing qualitative research (pp. 163-177). Newbury Park, CA: Sage.

Creswell, J.W. (2007). Qualitative inquiry and research design: choosing among five traditions. Thousand Oaks, CA: Sage.

Coffey, A. \& Atkinson, P. (1996). Making sense of qualitative data. Complementary research strategies. Thousand Oaks, CA: Sage.

Denzin, N.K. (1989). The research act. A theoretical introduction to sociological methods. Eaglewood Cliffs, NY: Prentice-Hall.

Denzin, N.K. \& Lincoln, Y.S. (2005). The Sage handbook of qualitative research. London: Sage.

Evers, J.C. (red.) (2007). Kwalitatief interviewen: kunst én kunde. Den Haag: LEMMA.

Evers, J.C. \& Staa, A.L. van (2010). Qualitative analysis in case study. In: Albert Mills, Gabrielle Durepos \& Elden Wiebe (Eds.), Encyclopedia of case study research. Part 2 (pp. 749757). Thousand Oaks, CA: Sage Publications.

Fereday, J. \& Muir-Cochrane, E. (2006). Demonstrating Rigor and Using Thematic Analysis: A Hybrid Approach of Inductive and Deductive Coding and Theme Development. International Journal of Qualitative Methods, 5(1).

Flick, U. (2006). An introduction to qualitative research. Thousand Oaks, CA: Sage.

Geertz, C. (1973). Thick Description: Toward an Interpretive Theory of Culture. In The interpretation of cultures: selected essays (pp. 3-30). New York: Basic Books.

Glaser, B.G. \& Strauss, A.L. (1967). The discovery of grounded theory. Chicago: Aldine.

Grbich, C. (2007). Qualitative data analysis. An introduction. London: Sage.

Kimchi, J., Polivka, B. \& Stevenson, J.S. (1991). Triangulation: Operational Definitions. Nursing Research, 40(6), 364-366.

LeComte, M.D. \& Schensul, J.J. (1999). Analyzing and interpreting ethnographic data. Walnut Creek, CA: Altamira Press.

Marshall, H. (2000). Avoid wrecked heads with magic and machinery: strategies for surviving the coding phase of qualitative research. Paper for the Annual Conference of the Australian Sociological Association.

Maso, I. \& Smaling, A. (1998). Kwalitatief onderzoek. Praktijk en theorie. Amsterdam: Boom.

Miles, M.B. \& Huberman, A.M. (1994). Qualitative data analysis. An expanded source book. Thousand Oaks: Sage.

Ritchie J. \& Spencer, L. (1993). Qualitative data analysis for applied policy research. In A. Bryman \& R. Burgess (Eds.), Analysing qualitative data (pp. 173-194). London: Routledge. Saldaña, J. (2009). The coding manual for qualitative researchers. London: Sage.

Strauss, A.L. (1987). Qualitative analysis for social scientists. Cambridge: Cambridge University Press.

Strauss, A.L. \& Corbin, J. (1998). Basics of qualitative research: techniques and procedures for developing grounded theory. Thousand Oaks, CA: Sage.

Wester, F. \& Peters, V. (2004). Kwalitatieve analyse. Uitgangspunten en procedures. Bussum: Coutinho. 